\title{
Foot Care Practices among Type 2 Diabetics Mellitus Patients Attending Diabetes Clinics in Embu County, Kenya
}

\author{
Annastacia M. Mbisi', Lucy K. Gitonga1, Silas Kiruki² \\ ${ }^{1}$ Department of Nursing, Chukka University, Nairobi, Kenya \\ ${ }^{2}$ Department of Physical Sciences, Chukka University, Nairobi, Kenya \\ Email: annahmbisi@gmail.com, gitonga30@yahoo.com, kirusila@yahoo.com
}

How to cite this paper: Mbisi, A.M., Gitonga, L.K. and Kiruki, S. (2019) Foot Care Practices among Type 2 Diabetics Mellitus Patients Attending Diabetes Clinics in Embu County, Kenya. Open Journal of Clinical Diagnostics, 9, 126-144.

https://doi.org/10.4236/ojcd.2019.94009

Received: August 8, 2019

Accepted: November 15, 2019

Published: November 18, 2019

Copyright () 2019 by author(s) and Scientific Research Publishing Inc. This work is licensed under the Creative Commons Attribution International License (CC BY 4.0).

http://creativecommons.org/licenses/by/4.0/

\section{Open Access}

\begin{abstract}
Diabetes mellitus has become a global epidemic of 21st century with disproportionately high socioeconomic burden in the developing world. Foot ulcerations secondary to peripheral neuropathy and peripheral vascular disease have led to devastating health outcomes including amputations. A descriptive survey targeting a sample size of 301 was drawn from the selected health facility. Majority of the respondents were female and aged between 40 and 70 years old. The duration that a patient had lived with diabetes, history of smoking and respondents age was significantly associated with foot ulcers at $\mathrm{P}$-value $<0.05$. Walking bare foot in and out of the house, breaking into new shoes, poor inspection of feet were associated with the development of foot ulcers while dressing of blisters with sterile dressings was associated with the prevention of foot ulcers.
\end{abstract}

\section{Keywords}

Diabetes Type 2, Foot Ulcers, Foot Self Care

\section{Introduction}

Diabetes mellitus (DM) is a common disease worldwide public health problem and diabetic foot ulcer (DFU) is among the complex and complications in patients with diabetes mellitus [1]. Globally, it was estimated that DM affected $8.3 \%$ of the patients [2]. Epidemiological diabetes survey done by World Health Organization [3] indicated the figure had gone up to 422 million worldwide by 2014. IDF their study done in 2015 projected the figure to reach 642 million by 2040 [2]. It is clear that this number can continue to go high, making DFU a 
major public health problem for the public. Diabetes mellitus is a chronic disease and is among the top four non-communicable diseases [NCDs]. Just like the other three NCDs (cardiovascular diseases (CVD), cancers, and chronic respiratory diseases), diabetes is of long duration and generally of gradual progression, World Health Organization [3].

\section{Literature Survey}

A meta-analysis study in various countries showed that the prevalence rate of DFU worldwide was $6.3 \%$. North America had the highest prevalence rate of $13.0 \%$, compared with Oceania with prevalence rate of 3.0\%. In Europe, the prevalence rate was $5.1 \%$, Australia had a prevalence rate of $1.5 \%$ and Belgium was found to have a prevalence of $16.6 \%$. While Canada had (14.8\%), USA had $13.0 \%$. India reported a prevalence rate of $11.6 \%$ [4].

In Africa, the number of patients suffering from diabetes has increased significantly and there are expectations of doubling the number in the coming decades. In 2015, an estimate of 14.2 million persons with diabetes in Africa was made and if the current trend continues the overall prevalence of diabetic foot ulcers was projected to increase to 34.2 million by the year 2040 [2]. International Diabetes Federation [2] also indicated in Africa, 21.5 million people live with diabetes with annual estimate of 480,900 diabetes-related deaths.

The most populous countries in the continent had the highest numbers of people with diabetes, these countries include; Ethiopia (1.9 million), Nigeria (3.9 million), South Africa (2.6 million), and the United Republic of Tanzania (1.7 million). However, the prevalence of diabetic foot ulcer was reported to be high in the island of Reunion (15.4\%), Seychelles (12.1\%), Gabon (10.7\%) and Zimbabwe (9.7\%) in descending prevalence [2] Recent meta-analysis study by Pengzi et al. [4] indicated that Africa showed a diabetes foot prevalence rate of $7.2 \%$ which is higher than Asia 5.5\%. Another study done by Abbas \& Archibald [5] indicated that the foot ulceration rates in Africa vary from one region to another and had been estimated to vary between $4 \%$ and $19 \%$. In Nigeria, another Hospital-based study revealed that the prevalence of lower limb ulceration was between $11 \%$ and $19.1 \%$, among individuals with diabetes [5] [6].

In Kenya, the prevalence of diabetes stood at 3.3\% in 2011 [2]. Mcferran [7] predicted to arise to $4.5 \%$ by 2025 . Recent studies done by Oduori \& Ondari [8] at Kenyatta national hospital indicate the overall prevalence of foot at risk was $76.1 \%$. There are many complications that affect people with diabetes, the foot ulcer complications take lead [9]. According to Chu and Wang [10], some patients developed foot ulcer after 1, 3, and 5 years and when their prevalence was examined they were increasing from $27.3 \%, 57.2 \%$, and $76.4 \%$, respectively, this also led to increase in prevalence of foot amputations at $12.5 \%, 22.3 \%$, and $47.1 \%$ respectively [10]. Other studies showed that the mortality rate as a result of diabetic foot amputation ranges from $13 \%$ to $40 \%$ within one year, at 3 years it was ranging from $35 \%$ to $65 \%$, and at 5 years it was ranging from $39 \%$ to $80 \%$, which was found to be worse than the mortality rate for most cancers [11]. Ac- 
cording to International Diabetes Federation [2], 50\% of these amputations are preventable if the patients are taught on the recommended daily foot care practices.

Prevention of foot ulcers and prophylactic foot care practices has been championed to minimise patient morbidity, the use of costly resources, and reduce chances for amputations [12]. It might take time and effort to establish good foot care practices, but foot self-care is very important. Regular inspection of the diabetic foot by patients along with recommended health education for patients is known to be one of the easiest, less expensive, and more effective measures for prevention of future foot ulcer complications [13]. Despite there being a large amount of literature resources on diabetic foot care practices and the importance of self foot care, published ones are limited especially on diabetes foot care practices, among patients with type 2 diabetes in Sub Saharan Africa, especially in Kenya.

Thus, this study was done to establish the current foot self-care practices among those patients who attend their diabetic clinics in Embu County. The information obtained from the study informed the county on the current level of use of self-foot care practices associated with strategies geared towards diabetic foot prevention, and help to improve the quality of care given to diabetic patients to minimise the burden related to diabetic foot complications. Health educating the patients on recommended strategies was likely to be effective if the patients were aware of their current practice on self-foot care. An analysis was done for 6 years on the effectiveness of preventive foot care practices and it revealed that those diabetic patients who had high chances of developing foot ulcers and were compliant with preventive practices were 13 times less likely to develop foot ulcers compared to those patients who did not follow the recommended guidelines. Among the patients who complied with the recommendations, the total cumulative incidence of foot ulcer was rated at $3.1 \%$ compared to $31.6 \%$ among those who did not comply [14].

\section{Problem Definition}

In Embu, Foot complications are a major source of morbidity related to diabetes and leading cause of admission to hospital among Type 2 diabetes mellitus patients in this area. Foot complications can be prevented and effectively managed but unfortunately, type 2 diabetes mellitus patients in this area seek medical attention regarding their feet when it's too late hence risk being amputated. This study therefore seeks to establish the gap through assessing foot care practices among this population, as understanding the main reasons behind this situation would be a step towards devising ways to alleviate it.

\section{Methodology}

The study was carried out at all diabetic clinics in Embu County which offers the specialized clinic. Embu County lies some 120 kilometers northeast of Nairobi, 
on south-eastern side of Mount Kenya. Embu County has four sub-county hospitals and one teaching and referral hospital. Out of the five hospitals only three offer diabetic clinic, that is, Kianjokoma and Runyenjes sub-county then the main referral hospital.

The study used a descriptive survey design to assess foot care practices among diabetic type 2 patients attending diabetic clinic in Embu County. The respondents of this study included all DM patients over 18years, who voluntarily consented to participate in the study and consent to give information.

The instrument of the study was a structured questionnaire, and direct observation/examination of the patient. The questionnaire contained socio-demographic data, and practice of foot self-care was administered to all the participants (patients) and the patients' feet were physically examined for foot ulceration to provide additional information on actual foot care practices.

The study population was 1413, with 954 attending Embu teaching and referral hospital, 234 attending Runyenjes sub-county hospital and 225 attending Kianjokoma sub-county hospital. The sample size was calculated using fisher et al. [15] formula through which a sample size of 301 participants arrived at.

During sampling, the researcher calculated proportional sample sizes per institution. A sample of 204 participants was drawn from Embu teaching and referral hospital, 50 participants were drawn from Runyenjes sub-county Hospital and 47 participants were selected from Kianjokoma sub-county hospital. In each facility, systematic random sampling was used to get the desired sample from daily type 2 register. The respondents signed informed consent before completing the questionnaire.

To ensure the reliability of the instrument, the research tools were pretested at Chuka general hospital on $10 \%(n=30)$ of 301 study participant. Parallel form technique was used to check how well the form elicits the same responses to the issues raised. To determine the content validity expert opinion was sought to judge whether or not the content and format of the instrument are appropriate.

Data were analysed using SPSS statistical software version 24. Descriptive statistics were computed to establish the characteristics of participants. Proportions were also computed and reported as percentage of totals. Chi-square test was used to test the relationship between categorical variables. Statistical significance was set at $\alpha=0.05$. A logistic regression model was used to predict the relationship between foot care practices and diabetes foot complication. Data was presented in summary tables.

Permission was sought from National Council for Science, Technology and Innovation ("NACOSTI") and Embu Teaching and Referral Hospital (ETRH) institutional research board committee before the execution of the research. Consent was obtained from the respondents in order to participate in the study; those not wishing to participate were not forced to participate in the study. Confidentiality of the information gathered from the subjects was maintained and no subject was required to write his or her name. Data collected was stored in 
password database to prevent any unauthorized access.

\section{Results Presentation}

\subsection{Socio-Demographic Profile of the Respondents}

The ages of the respondents ranged from 40 to 89 complete years with a mean age of 63 years.

According to the results in Table 1, on social-demographic characteristic; More than half of the participants (51.2\%) were aged between 50 and 70 years of age, while the remaining $(10.8 \%)$ were aged between 40 and 50 years and $38 \%$ of the participants had their age above 70 years. Most of the patients were aware of the topic under study; however increase in age was associated with minimal or low level of awareness of diabetic foot care, on gender, $112(37.7 \%)$ were male participants while the remaining $62.3 \%$ were female. More females were found to attend the diabetic clinics compared to their counterpart male patients. Expectedly majority of the respondents were married (70\%), while the remaining

Table 1. Socio-demographic characteristics of the respondents.

\begin{tabular}{|c|c|c|c|}
\hline Variable & category & frequency & percentage \\
\hline \multirow[t]{4}{*}{ Age in years } & Above 70 & 113 & 38 \\
\hline & $60-70$ & 97 & 32.7 \\
\hline & $50-60$ & 55 & 18.5 \\
\hline & $40-50$ & 32 & 10.8 \\
\hline \multirow[t]{2}{*}{ Gender } & Male & 112 & 37.7 \\
\hline & Female & 185 & 62.3 \\
\hline \multirow[t]{3}{*}{ Marital status } & Single & 13 & 4,4 \\
\hline & married & 208 & 70 \\
\hline & Separated, windowed and divorced & 76 & 25.6 \\
\hline \multirow[t]{4}{*}{ Level of education } & Informal education & 54 & 18.2 \\
\hline & Primary education & 142 & 47.8 \\
\hline & Secondary education & 82 & 27.6 \\
\hline & Tertiary education & 19 & 6.4 \\
\hline \multirow[t]{4}{*}{ Source of income } & Farming & 217 & 73.1 \\
\hline & Formal employment & 15 & 5.1 \\
\hline & Informal employment & 61 & 20.5 \\
\hline & Unemployed & 4 & 1.3 \\
\hline \multirow[t]{2}{*}{ Smoking } & Past smoker & 73 & 24.6 \\
\hline & Never smoked & 224 & 75.4 \\
\hline \multirow{2}{*}{$\begin{array}{l}\text { Chewing or taking oral } \\
\text { tobacco }\end{array}$} & Took in the past & 5 & 1.7 \\
\hline & Never taken oral tobacco & 292 & 98.3 \\
\hline
\end{tabular}


$25.5 \%$ were separated, widowed or divorced and the remaining $4.4 \%$ were single.

Majority of the respondents 142 (47.8) were of primary level of education, with $27.6 \%$ with secondary level of education and $6.4 \%$ with post-secondary level of education. In the same report a few of the respondents, 54 (18.2\%) had informal level of education and the researcher had to translate the questionnaire for them to understand

On source of income, most of the respondents 217 (73.1\%) reported to receive their main finances from farming, with 5.1\% having formal employment, $20.5 \%$ with informal employment and $1.3 \%$ were not employed yet depended on support from other family members. It was evident that the patients regardless of the source of income, they were comfortable with the amount earned.

On their social life, $24.6 \%$ reported to have smoked in the past, $75.4 \%$ never smoked and none of the respondents voluntarily reported to be smoking currently. Smoking is associated with deposition of nicotine into blood circulation which impairs the normal circulation of blood. Those who ever smoked, reported to have smoked a range of one to twenty sticks of cigarettes per day. A non-significant proportion among the smokers had taken per oral tobacco, 5 (1.7\%) but none reported to be taking oral tobacco currently.

On clinical characteristics of the patients as shown in Table 2, 35 (11.8\%) had suffered from diabetes for less than 5 years, 25.9\% between 6 and 10 years, 34\% between 11 - 15 years and $28.3 \%$ above 15 years. On checking the body mass index (BMI) of the patients, $4.4 \%$ between 18.5 and 24.5 which was considered to be normal, $56.6 \%$ their BMI being between 24.5 and 30 which was regarded as overweight and $39 \%$ had their BMI above 30 which was interpreted as

Table 2. Clinical characteristics of the respondents.

\begin{tabular}{cccc}
\hline Variable & Category & Frequency & Percentage \\
\hline $\begin{array}{c}\text { Duration since first time diagnosis as } \\
\text { diabetic }\end{array}$ & $<5$ years & 35 & 11.8 \\
& $6-10$ years & 77 & 25.9 \\
Current BMI & $11-15$ years & 101 & 34 \\
& $>15$ years & 84 & 4.4 \\
& $18.5-24.5$ & 13 & 56.6 \\
Type of diabetes treatment on & $24.5-30$ & 168 & 39 \\
& Oral anti-diabetes & 195 & 65.7 \\
Had other foot complication & Insulin & 30 & 10.1 \\
Had foot complication & combined & 72 & 24.3
\end{tabular}


being obese.

Majority of the patients 195 (65.7\%) were on oral antidiabetics while the remaining proportion $24.2 \%$ were on combined therapy. It was reported that majority of those who were on insulin therapy $30(10.1 \%)$ had been recently started on the therapy since oral medication had failed to control their blood sugars.

On history taking, 215 (72.4\%) reported to have had foot complications, out of those who had foot complications 145 (67.5\%) were found to have foot ulcer, $70(32.5 \%)$ had other foot complication such edema, corns among others while others reported non-specific problems.

On checking association of socio-demographic and clinical characteristics factors with development of foot ulcer, Table 3 shows the variables that were significantly associated with foot ulcer development among the respondent. Among the respondents, 113 patients were aged above 70 years, out of all these 68 had developed foot ulcer while 45 never had foot ulcer. Those of age bracket 40 - 50, 17 of them had foot ulcers while 15 were free of foot ulcers. In the age bracket of $50-60,27$ had foot ulcer with 28 without foot ulcers and those in the age bracket of 60 - 70 were 97, out of these, 39 had developed foot ulcers while the remaining had not suffered the complication. $\chi^{2}(3, \mathrm{~N}=297)=8.464, \mathrm{P}=$ 0.037 . This meant that age was a predictor of developing foot ulcer; those with advanced age were at risk of developing the foot ulcer.

Smoking is a risk factor for development of foot complications among patients with type 2 diabetes. This became evident in this study. Out of 297 respondents, only 73 had reported to be past smokers. 46 of the 73 respondents, who were past smokers, had developed foot ulcers. The numbers of those who were nonsmokers were averagely the same between those who developed foot ulcers and those who didn't. There was a strong association between smoking and history of smoking with development of foot ulcers $\chi^{2}(1, \mathrm{~N}=297)=5.738 \mathrm{P}$

Table 3. Significant socio-demographic and clinical factors associated with foot ulcer development.

\begin{tabular}{|c|c|c|c|c|c|}
\hline \multirow{2}{*}{ Variable } & \multirow{2}{*}{ category } & \multicolumn{2}{|c|}{ Has foot ulcer } & \multirow{2}{*}{$\mathrm{df}$} & \multirow{2}{*}{$\mathrm{P}$-value } \\
\hline & & Yes & No & & \\
\hline \multirow[t]{4}{*}{ Age in years } & $>70$ & 68 & 45 & \multirow{4}{*}{3} & \multirow{4}{*}{$\begin{array}{c}\mathrm{P}=0.037 \\
\mathrm{X}^{2}=8.464\end{array}$} \\
\hline & $60-70$ & 39 & 58 & & \\
\hline & $50-60$ & 27 & 28 & & \\
\hline & $40-50$ & 17 & 15 & & \\
\hline \multirow[t]{2}{*}{ Smoking status } & Past smoker & 46 & 27 & \multirow[b]{2}{*}{2} & $\mathrm{P}=0.017$ \\
\hline & Never smoked & 105 & 119 & & $\mathrm{X}^{2}=5.738$ \\
\hline \multirow{4}{*}{$\begin{array}{l}\text { Number of years } \\
\text { with diabetes }\end{array}$} & Less than 5 years & 15 & 20 & \multirow{4}{*}{3} & \multirow{4}{*}{$\begin{aligned} \mathrm{P} & =0.003 \\
\mathrm{X}^{2} & =13.722\end{aligned}$} \\
\hline & $6-10$ years & 33 & 44 & & \\
\hline & $11-15$ years & 46 & 55 & & \\
\hline & Greater than 15 year & 57 & 27 & & \\
\hline
\end{tabular}


$=0.017$. Chewing or taking oral tobacco was not associated with development of foot ulcers.

The number of years a respondent had lived with diabetes was significantly associated with development of foot ulcers. Those who had lived for more than 15 years with diabetes were at a higher risk of developing foot ulcers. In this study, 35 respondents had lived with diabetes for less than 5 years and only 15 had developed foot ulcers. Those who had lived with diabetes for $6-10$ years were 77 and 33 out of these had developed foot ulcers. A relatively high number of respondents 101, had lived with diabetes for 11 to 15 years, among these 46 had developed foot ulcers. Those who had lived with diabetes for more than 16 years were 84 and more than half of them, 57 had developed foot ulcers $\chi^{2}(3, \mathrm{~N}$ $=297)=13.722, \mathrm{P}=0.003$.

\subsection{Practices of Foot Self-Care}

On practice of foot self-care, the patient is expected to optimize their metabolic glucose levels, patients should be screened and educated on best foot self-care practices. These practices include but not limited to foot ulcer preventive practices such as washing the feet regularly, drying the feet and between the toes among others; examination of feet for any risk factors such as skin color, presence of infected toes, toe nail appearance etc. and appropriate foot wear. The participants were subjected to twenty-five multiple choice questions which were tailored to assess the actual practice of best foot self-care practices.

According to the results shown in Table 4, practice of foot care among the respondents was categorized into poor, moderate and good by calculating the sum of activities practiced by each respondent. Those who carried out between $0 \%-57 \%$ were rated to have poor practice, those who carried out between $58 \%$ $71 \%$ were rated to have moderate practice and those who carried between $72 \%$ and above were classified as to have good foot self-care practice. The number of respondents with poor practice was $45.1 \%$, those with moderate practice were $41.4 \%$ and the remaining had good foot care practice. Generally, the respondents were found to have averagely good practice.

On checking the association between general practice and development of foot ulcer, Table 5 shows the results. Whereby generally, out of 134 patients who had poor practice 81 of them developed foot ulcers. Out of 123 who moderately practiced self-foot care, 69 developed foot ulcers. Forty patients had good practice and only 16 of them developed foot ulcer. Therefore good practice of self-foot care was associated with prevention of foot ulcers $\chi^{2}(2, \mathrm{~N}=297)=$

Table 4. Level of practice of foot self-care.

\begin{tabular}{cccc}
\hline Variable & Category & Frequency & Percentage \\
\hline & Poor & 134 & 45.1 \\
Level of practice of foot self-care & Moderate & 123 & 41.4 \\
& Good & 40 & 13.5 \\
\hline
\end{tabular}


Table 5. Association between general practice and development of foot ulcer.

\begin{tabular}{ccccccc}
\hline \multirow{2}{*}{ Variables } & Category & \multicolumn{2}{c}{ Has foot ulcer } & & df & P-value \\
\cline { 3 - 4 } & Poor & 53 & 81 & & \\
\hline \multirow{3}{*}{ General practice of foot care } & Average & 54 & 69 & 2 & $\begin{array}{c}\text { Pes } \\
\end{array}$ \\
& Good & 24 & 16 & & $\chi^{2}=9.010$ \\
\hline
\end{tabular}

9.198, $\mathrm{P}=0.010$

The participants were exposed to 25 multiple questions and the results were as shown in Table 6, which is explained below.

The participants were asked on how frequent they examine their feet, majority of the respondents reported to have examined their feet once a day, $74.1 \%$, $17.5 \%$ less than five times a week, $0.7 \%$ did it more than once a day, and $7.7 \%$ reported to examine their feet once a week or less. On checking the shoes for any object that can injure the feet, $8.8 \%$ reported to check their shoes often, $53.8 \%$ sometimes checked, $37.4 \%$ reported to rarely check their shoes before wearing. Majority of the respondents 160 (53.9\%), reported to sometimes check their shoes before wearing them, $37.4 \%$ rarely checked, while $8.8 \%$ of the respondents often checked their shoes before wearing them. The patients are expected to check their shoes when taking them off to ensure there is no sharp object impeded on the shoes. Less than half of the participants 10 (3.4\%), reported to often check their shoes when taking them off, $34 \%$ rarely checked, $60.3 \%$ sometimes checked, and $2.4 \%$ never checked.

Washing of the feet of a diabetic patient is of paramount importance, $1 \%$ of the respondents in this study reported to wash their feet more than once a day, $89.2 \%$ once a day, and $9.8 \%$ most days a week. Generally, $1 \%$ dries their feet often after washing, $48.8 \%$ sometimes dry their feet, $43.4 \%$ rarely dry their feet and $6.7 \%$ never dries their feet after washing. On probing further in drying between toes, after washing, $8.4 \%$ ensures their feet are dry especially between the toes always, $44.1 \%$ sometimes check if they are dry sometimes not, $19.2 \%$ often ensure that the space between their toes is dry and $28.3 \%$ never checks in between the toes to check if its dry.

It was found that $63.3 \%$ of the participants use a moisturizing cream on their feet daily, $17.2 \%$ use the cream once a week, $13.1 \%$ once a month and $6.4 \%$ never use a cream between their toes. In the same line, 5.4\% use a moisturizing cream between their toes daily, $34.7 \%$ once a week, $3 \%$ once a month and $56.9 \%$ never applied the cream between their toes at all.

The respondents reported to trim their toenails as they grew longer. $3 \%$ reported to trim their nails most of the time, $45.5 \%$ once a month, $48.8 \%$ less than a month and $2.7 \%$ never trimmed their toe nails. $1.7 \%$ reported to wear slippers with no fasteners most of the time, while $78.1 \% .13 .8 \%, 6.4 \%$ wear them sometimes, rarely and never respectively. It was reported that some patient wear trainers. On this, $0.7 \%$ proportion of the respondents was found to wear trainers 
Table 6. Specific diabetic foot self-care practices among the respondents.

\begin{tabular}{|c|c|c|c|}
\hline Variable & Category & Frequency & Percentage \\
\hline \multirow[t]{4}{*}{ Examination of feet } & Once a week or less & 23 & 7.7 \\
\hline & Less than 5 times a week & 52 & 17.5 \\
\hline & Once a week & 220 & 74.1 \\
\hline & More than once a day & 2 & 0.7 \\
\hline \multirow[t]{3}{*}{ Checking shoes before wearing them } & Rarely & 111 & 37.4 \\
\hline & Sometimes & 160 & 53.8 \\
\hline & often & 26 & 8.8 \\
\hline \multirow[t]{4}{*}{ Checks shoes when taking them off } & Never & 7 & 2.4 \\
\hline & Rarely & 179 & 34 \\
\hline & Sometimes & 101 & 60.3 \\
\hline & Often & 10 & 3.4 \\
\hline \multirow[t]{3}{*}{ Frequency of washing feet } & Most days of the week & 29 & 9.8 \\
\hline & Once a day & 265 & 89.2 \\
\hline & More than once a day & 3 & 1 \\
\hline \multirow[t]{4}{*}{ Ensures feet are dry after washing } & Never & 20 & 6.7 \\
\hline & Rarely & 129 & 43.4 \\
\hline & Sometimes & 145 & 48.8 \\
\hline & Often & 3 & 1 \\
\hline \multirow[t]{4}{*}{ Ensures between toes are dry } & Never & 84 & 28.3 \\
\hline & Sometimes & 131 & 44.1 \\
\hline & Often & 57 & 19.2 \\
\hline & Always & 25 & 8.4 \\
\hline \multirow[t]{4}{*}{ Use of moisturizing cream on feet } & Never & 19 & 6.4 \\
\hline & Once a month & 39 & 13.1 \\
\hline & Once a week & 51 & 17.2 \\
\hline & Daily & 188 & 63.3 \\
\hline \multirow{4}{*}{$\begin{array}{l}\text { Use of moisturizing cream between } \\
\text { toes }\end{array}$} & Daily & 16 & 5.4 \\
\hline & Once a week & 103 & 34.7 \\
\hline & Once a month & 9 & 3 \\
\hline & Never & 169 & 56.9 \\
\hline \multirow[t]{3}{*}{ Frequency of washing feet } & Most days of the week & 29 & 9.8 \\
\hline & Once a day & 265 & 89.2 \\
\hline & More than once a day & 3 & 1 \\
\hline \multirow[t]{4}{*}{ Ensures feet are dry after washing } & Never & 20 & 6.7 \\
\hline & Rarely & 129 & 43.4 \\
\hline & Sometimes & 145 & 48.8 \\
\hline & Often & 3 & 1 \\
\hline
\end{tabular}




\section{Continued}

\begin{tabular}{|c|c|c|c|}
\hline \multirow[t]{4}{*}{ Ensures between toes are dry } & Never & 84 & 28.3 \\
\hline & Sometimes & 131 & 44.1 \\
\hline & Often & 57 & 19.2 \\
\hline & Always & 25 & 8.4 \\
\hline \multirow[t]{4}{*}{ Use of slipper with no fastening } & Most of the time & 5 & 1.7 \\
\hline & Sometimes & 232 & 78.1 \\
\hline & Rarely & 41 & 13.8 \\
\hline & Never & 19 & 6.4 \\
\hline \multirow[t]{4}{*}{ Frequency of trimming toe nails } & Never & 8 & 2.7 \\
\hline & Less than once a month & 145 & 48.8 \\
\hline & Once a month & 135 & 45.5 \\
\hline & Most of the time & 9 & 3 \\
\hline \multirow[t]{4}{*}{ Wearing of trainers } & Never & 42 & 14.1 \\
\hline & Rarely & 178 & 59.9 \\
\hline & Sometimes & 75 & 25.3 \\
\hline & Most of the time & 2 & 0.7 \\
\hline \multirow{4}{*}{$\begin{array}{l}\text { Wearing shoes with lace-up strap } \\
\text { fastening }\end{array}$} & Never & 6 & 2 \\
\hline & Rarely & 140 & 47.2 \\
\hline & Sometimes & 139 & 46.8 \\
\hline & Most of the time & 12 & 4 \\
\hline \multirow[t]{4}{*}{ Wearing pointed shoes } & Most of the time & 10 & 3.4 \\
\hline & Sometimes & 128 & 43.1 \\
\hline & Rarely & 74 & 24.9 \\
\hline & Never & 85 & 28.6 \\
\hline \multirow[t]{4}{*}{ Wearing of flip -flop or mules } & Most of the time & 4 & 1.3 \\
\hline & Sometimes & 223 & 75.1 \\
\hline & Rarely & 48 & 16.2 \\
\hline & Never & 22 & 7.4 \\
\hline \multirow[t]{4}{*}{ Breaking in new shoes gradually } & Never & 82 & 27.6 \\
\hline & Sometimes & 159 & 53.5 \\
\hline & Most of the time & 55 & 18.5 \\
\hline & Always & 1 & 0.3 \\
\hline \multirow[t]{4}{*}{ Wearing artificial fiber socks } & Most of the time & 2 & 0.7 \\
\hline & Sometimes & 169 & 56.9 \\
\hline & Rarely & 73 & 24.6 \\
\hline & Never & 53 & 17.8 \\
\hline Wearing shoes without socks & Often & 29 & 9.8 \\
\hline
\end{tabular}




\section{Continued}

\begin{tabular}{|c|c|c|c|}
\hline & Sometimes & 152 & 51.2 \\
\hline & Rarely & 65 & 21.9 \\
\hline & Never & 51 & 17.2 \\
\hline \multirow[t]{4}{*}{ Frequency of changing socks } & Less than 4 times a week & 1 & 0.3 \\
\hline & 4 - 6 times a week & 23 & 7.7 \\
\hline & Daily & 271 & 91.2 \\
\hline & More than once a week & 2 & 0.7 \\
\hline \multirow[t]{4}{*}{ Walking in the house bare foot } & Often & 6 & 2 \\
\hline & Sometimes & 210 & 70.7 \\
\hline & Rarely & 66 & 22.2 \\
\hline & Never & 15 & 5.1 \\
\hline \multirow[t]{4}{*}{ Walking in the house bare foot } & Often & 6 & 2 \\
\hline & Sometimes & 271 & 70.7 \\
\hline & Rarely & 66 & 22.2 \\
\hline & Never & 15 & 5.1 \\
\hline \multirow[t]{4}{*}{ Walking outside the house barefoot } & often & 4 & 1.3 \\
\hline & Sometimes & 153 & 51.5 \\
\hline & Rarely & 108 & 36.4 \\
\hline & Never & 32 & 10.8 \\
\hline \multirow[t]{3}{*}{ Use of hot bottles in the bed } & Sometimes & 73 & 24.6 \\
\hline & rarely & 32 & 10.8 \\
\hline & Never & 192 & 64.6 \\
\hline \multirow[t]{4}{*}{ Use of radiator to warm body } & often & 1 & 0.3 \\
\hline & sometimes & 119 & 40.1 \\
\hline & rarely & 38 & 12.8 \\
\hline & Never & 139 & 46.8 \\
\hline \multirow[t]{4}{*}{ Use of remedies when one has a cones } & often & 14 & 4.7 \\
\hline & Sometimes & 187 & 63 \\
\hline & Rarely & 53 & 17.8 \\
\hline & Never & 43 & 14.5 \\
\hline \multirow[t]{4}{*}{ Use of dry dressing on blisters } & Never & 27 & 9.1 \\
\hline & Rarely & 153 & 51.5 \\
\hline & sometimes & 103 & 34.7 \\
\hline & often & 14 & 4.7 \\
\hline \multirow{4}{*}{$\begin{array}{l}\text { Use of dressing when one has a cut, } \\
\text { gaze or burn }\end{array}$} & Never & 34 & 11.4 \\
\hline & Rarely & 139 & 46.8 \\
\hline & Sometimes & 100 & 33.7 \\
\hline & Often & 24 & 8.1 \\
\hline
\end{tabular}


most of the time, $25.3 \%$ sometimes wear trainers, $59.9 \%$ rarely were they found wearing trainers and $14.1 \%$ never wore trainers at all.

On the type of shoes worn by the participants, $4 \%$ wore shoes with lace-up or strap fasteners most of the time, $46.8 \%$ sometimes wore such shoes, $47.2 \%$ rarely wore shoes with fasteners or lace-ups and $2 \%$ never wore such shoes. It was also reported that there was the use of pointed shoes among the participants, $3.4 \%$ reported to have worn pointed shoes most of the time, $43.1 \%$ some times, $24.9 \%$ rarely and $28.6 \%$ never wore pointes shoes. Use of mules or flip-flops wear was also assessed whereby $1.3 \%$ reported to have worn the mules most of the time, $75.1 \%$ some times, $16.2 \%$ rarely and $7.4 \%$ never wore mules.

New shoes were considered to be tight, therefore the frequency of wearing or breaking in new shoes was assessed. Gradual breaking in of new shoes was reported to be the good practice for diabetic patients, $0.3 \%$ reported to gradually break in new shoes always, $18.5 \%$ most of the time, $53.5 \%$ sometimes and $27.6 \%$ rarely or never.

The type of socks worn by an individual affects blood circulation especially to the foot. In this study, $0.7 \%$ was found to wear artificial fibre socks (nylon) most of the time, $56.9 \%$ reported to wear artificial fiber socks sometimes, $24.6 \%$ rarely wore nylon socks and $17.8 \%$ never wore artificial fiber socks. Majority of the respondents, $51.2 \%$ sometimes wore shoes without socks, $21.9 \%$ rarely wore shoes without socks, $17.2 \%$ never wore shoes without socks or tights and $9.8 \%$ often wore shoes without sock or stockings or tights. The participants were asked to indicate the frequency of changing their socks and $0.7 \%$ reported to change their socks more than once a week, $91.2 \%$ daily change their socks, $7.7 \%$ 4 - 6 times a week and $0.3 \%$ reported to change their socks less than four times a week.

It was also noted that a number of participants were walking bare foot at home. $2 \%$ reported to often walk bare foot in the house, $70.7 \%$ sometimes walk bare foot in the house, $22.2 \%$ rarely walk bare foot and $5.1 \%$ never walk bare foot in the house. $1.3 \%$ reported to often walk bare foot outside the house, $51.5 \%$ sometimes walk bare foot outside the house, 36.4\% rarely walk bare foot and $10.8 \%$ never walk bare foot outside the house. Hot water bottles use in bed is a practice that helps to promote blood circulation especially the lower extremities. In this study, the participants were found to be aware on the same. $24.6 \%$ sometimes use the hot water bottle, $10.8 \%, 64.6 \%$ rarely use and others never use the hot water bottle respectively.

Warming oneself especially during a cold season is crucial to avoid numbness, in this study it was found that $0.3 \%$ of the participants often put their feet near the fire or on a radiator; $40.1 \%$ sometimes put their feet near the fire or radiator while $12.8 \%$ rarely put their feet near the fire or on a radiator. A relatively high proportion, $46.8 \%$ was reported never put their feet near the fire or on a radiator.

Use of corn remedies, corn plaster or paints is common among the general population especially in treating a corn. This practice was evaluated among the 
diabetic patients who participated in this study. $4.7 \%$ were found to have often used corn remedies/corn plaster or paints, $17.8 \%$ rarely used the corn remedies, $63 \%$ sometimes and $14.5 \%$ never used the corn remedies. It was also reported that $4.7 \%$ often use a dry dressing on a blister or burn when they get one, $34.7 \%$ sometimes puts a dry dressing on the blister in case they get one, 51.5\%, 9.1\% rarely and never uses a dry dressing to cover a blister when they get one.

In case a respondent had a cut, gaze or burn it was recommended to use a dry dressing. In the study, $11.4 \%$ reported to never use, $46.8 \%$ to rarely use, $33.7 \%$ sometimes used and $8.1 \%$ of the respondents were willing and other used it often.

The twenty five multiple questions on foot care practices that participants were subjected to, only a few were found to be significantly associated with development of foot ulcer. Table 7 indicates specific foot self-care practices associated with development of foot ulcer.

Table 7. Specific foot self-care preventive practices associated with development of foot ulcer.

\begin{tabular}{|c|c|c|c|c|c|}
\hline \multirow{2}{*}{ Variables } & \multirow{2}{*}{ Category } & \multicolumn{2}{|c|}{ Has foot ulcer } & \multirow{2}{*}{$\mathrm{df}$} & \multirow{2}{*}{$\mathrm{P}$-value } \\
\hline & & No & Yes & & \\
\hline \multirow{4}{*}{$\begin{array}{l}\text { Drying of the feet after } \\
\text { washing }\end{array}$} & Never & 7 & 13 & \multirow{4}{*}{3} & \multirow{4}{*}{$\begin{array}{l}\mathrm{P}=0.037 \\
\mathrm{X}^{2}=8.510\end{array}$} \\
\hline & Rarely & 56 & 73 & & \\
\hline & Sometimes & 80 & 65 & & \\
\hline & Often & 3 & 0 & & \\
\hline \multirow{4}{*}{ Drying feet between toes } & Never & 26 & 58 & \multirow{4}{*}{2} & \multirow{4}{*}{$\begin{aligned} \mathrm{P} & =0.000 \\
\mathrm{X}^{2} & =27.822\end{aligned}$} \\
\hline & Sometimes & 62 & 69 & & \\
\hline & Often & 38 & 19 & & \\
\hline & Always & 20 & 5 & & \\
\hline \multirow{3}{*}{$\begin{array}{l}\text { Applying moisturizing } \\
\text { cream between the toes }\end{array}$} & Daily & 3 & 13 & \multirow{3}{*}{3} & \multirow{3}{*}{$\begin{array}{c}P=0.022 \\
X^{2}=9.672\end{array}$} \\
\hline & Once a week & 51 & 52 & & \\
\hline & Once a month & 2 & 7 & & \\
\hline \multirow{4}{*}{ Walking barefoot } & Never & 9 & 5 & \multirow{4}{*}{3} & \multirow{4}{*}{$\begin{aligned} \mathrm{P} & =0.012 \\
\mathrm{X}^{2} & =11.024\end{aligned}$} \\
\hline & Rarely & 43 & 25 & & \\
\hline & Sometimes & 93 & 116 & & \\
\hline & Often & 1 & 5 & & \\
\hline \multirow{4}{*}{$\begin{array}{l}\text { Wearing shoes without } \\
\text { socks }\end{array}$} & Never & 31 & 20 & \multirow{4}{*}{3} & \multirow{4}{*}{$\begin{aligned} \mathrm{P} & =0.000 \\
\mathrm{X}^{2} & =18.281\end{aligned}$} \\
\hline & Rarely & 36 & 29 & & \\
\hline & Sometimes & 75 & 77 & & \\
\hline & Often & 4 & 25 & & \\
\hline \multirow{4}{*}{$\begin{array}{l}\text { Putting a dressing on a } \\
\text { blister }\end{array}$} & Never & 7 & 21 & \multirow{4}{*}{3} & \multirow{4}{*}{$\begin{aligned} \mathrm{P} & =0.006 \\
\mathrm{X}^{2} & =12.336\end{aligned}$} \\
\hline & Rarely & 76 & 77 & & \\
\hline & Sometimes & 51 & 50 & & \\
\hline & Often & 12 & 3 & & \\
\hline
\end{tabular}


Drying of the feet after washing, three respondents were often drying their feet and none of them got foot ulcer. 145 respondents sometimes ensured their feet were dry after washing and 65 of them developed foot ulcer. 129 respondents rarely ensured their feet were dry and 73 of them got foot ulcers. This implied that, those who rarely dry their feet were at risk of getting foot ulcers. 20 respondents stated that they never dry their feet after washing. Out of the 20, 13 developed foot ulcers. Therefore the practice of drying feet after washing them was considerably linked to the prevention of foot ulcers development. Those who dry the feet were less likely to develop foot ulcer with a Phi Cramer's value of 0.169. On Chi-square the results were significant $\chi^{2}(3, \mathrm{~N}=297)=8.510, \mathrm{P}=0.037$.

Drying the feet between toes was also assessed. 84 participants never dried their feet between the toes. Majority of those who didn't dry the feet between their toes (58) developed foot ulcers. Out of 131 participants who sometimes dried their feet between the toes 69 developed foot ulcers. There were those who often dried their feet between toes. Among the 57 who ensured they often dry their feet between toes, only 19 developed foot ulcers. This indicates that drying of feet between toes prevents development of foot ulcers. These results were significantly associated with development of foot ulcer $\chi^{2}(3, \mathrm{~N}=297)=27.822, \mathrm{P}=$ 0.000 . Nominal by nominal association between those participants who dry their feet between the toes and those who developed foot ulcers was significant at Phi Cramer's value of $0.306, P=0.000$. Application of moisturizing cream on feet between the toes was also significantly associated with development of foot ulcers $\chi^{2}(3, \mathrm{~N}=297)=9.672, \mathrm{P}=0.022$.

Walking bare foot was associated with development of foot ulcers. Out of 6 respondents who often walked bare foot, 5 developed foot ulcer. 209 respondents sometimes were walking bare foot, and 116 of them developed foot ulcers. Out of 14 respondents who never walked bare foot, only five developed foot ulcer. 68 participants rarely walked bare foot and amongst them 25 developed foot ulcer. It was evident from the findings that walking bare foot predisposes an individual to develop foot ulcer $\chi^{2}(3, \mathrm{~N}=297)=11.024, \mathrm{P}=0.012$.

Wearing of socks is important among diabetic patients. On assessment, 29 (9.8\%) of the respondents were wearing shoes without socks often. Out of these 25 developed feet ulcers. Out of 152 who sometimes wore shoes without socks, 77 developed foot ulcer. 65 participants rarely wore shoes without socks and only 29 developed foot ulcer. For the 51 who never wore shoes without socks, only 20 developed foot ulcers $\chi^{2}(3, \mathrm{~N}=297)=18.281, \mathrm{P}=0.000$.

The respondents were asked if they put a dressing on any blister they develop. From the responses, out of 28 who never put a dressing on the blister, 21 developed a foot ulcer from the blister. Out of 153 who rarely put a dressing, 77 developed foot ulcer. However, out of 15 who often ensure that the blister is dressed, only 3 developed foot ulcer. These findings indicate that if all the blisters are dressed, the risk of developing foot ulcer decreases. Dressing of the blister was significantly associated with prevention of foot ulcer development $\chi^{2}(3$, 
$\mathrm{N}=297)=12.336, \mathrm{P}=0.006$.

\subsection{Risk Factors for Developing Foot Ulcer}

In this study, some risk factors were found to be positively associated with development of foot ulcers.

The participant were further done examination on their feet using a checklist, the results are as indicated in Table 8. Surprisingly majority (85.9\%) of the participants had their nails not cut to the shape of the toe, followed by quite a number, $224(75.4 \%)$ whose the skin between the toes were moist. The moist skin predisposes the patient to development of sore between the toes. This tends to support the idea of the large number with sores, 122 (41.1\%) and other foot complication, 212 (71.4\%) respectively. It was also observed that, considerable number $180(60.6 \%)$. of the patient had present of rough edges or corner on their toe nail, others had callus, 124 (41.8\%), fissures 76 (25.5\%), dry skin 50 $(16.8 \%)$ on their feet.

\subsection{Type of Foot Wear Used by Respondents}

On checking the type of foot wear used by the respondents, Table 9 presents the results that, $25.3 \%$ had shoes with soft upper wear, 36.4\% soft insoles, $26.3 \%$ wore lace up shoes, $0.3 \%$ wore boots, $38.7 \%$ were on sneakers or rubber shoes, $0.3 \%$ had were in high heeled shoes, $5.1 \%$ were wearing sandals, $28.3 \%$ wore rubber slippers/flip-flop, $0.7 \%$ had custom made shoes and $0.3 \%$ were wearing plastic shoes.

\section{Discussion of Results}

In this study, walking bare foot and dressing of blisters with sterile dressing was

Table 8. Risk factors for development of foot ulcer.

\begin{tabular}{ccc}
\hline Variable & Frequency & Percentage \\
\hline Presence of fissures & 76 & 25.6 \\
Presence of infected toe nail & 12 & 4 \\
Presence of callus or corn & 124 & 41.8 \\
Presence of blisters & 2 & 0.7 \\
Presence of abrasion & 3 & 1 \\
Presence of sores & 122 & 41.1 \\
Has other foot complications & 212 & 71.4 \\
Dry skin & 50 & 16.8 \\
Moist skin between the toes & 224 & 75.4 \\
Toe nails not cut to the shape of the toe & 255 & 85.9 \\
Presence of rough edges or corners & 180 & 60.6 \\
Presence of ingrown & 21 & 7.1 \\
Presence of infected ingrown & 8 & 2.7 \\
\hline
\end{tabular}


Table 9. Type of shoes used by the respondents on the time of study.

\begin{tabular}{ccc}
\hline Variable & Frequency & Percentage \\
\hline Soft upper foot wear & 75 & 25.3 \\
Soft insoles & 108 & 36.4 \\
Lace up closed shoes & 78 & 26.3 \\
Wore boots & 1 & 0.3 \\
Wearing sneakers/ rubber shoes & 115 & 38.7 \\
Wearing high heeled shoes & 1 & 0.3 \\
Wearing sandals & 15 & 5.1 \\
Wearing rubber slippers/flip-flop & 84 & 28.3 \\
Wearing custom made shoes & 2 & 0.7 \\
Wearing plastic shoes & 1 & 0.3 \\
\hline
\end{tabular}

significantly associated with foot ulcers. Those patients, who reported to be walking bare foot in and out of the house, were prone to develop foot ulcers compared to those who wore shoes. Walking bare foot was linked to risk of foot injury which can develop into foot ulcer. Out 14 who never walked bare foot only 5 developed foot ulcer but those who sometimes walked bare foot out of 209,116 developed foot ulcer. These results concur with those reported by Taksande, Thote, \& Jajoo [16] in a study on attitude, practice, and knowledge on foot care among patients with diabetes at central rural India which showed that bare foot walking increases chance of developing foot ulcer.

Those patients who reported presence of a blister to a health care worker and had it dressed, rarely developed foot ulcers compared to those patients who ignored the blister to heal on its own. $4.7 \%$ often applied a dressing while $34.7 \%$ sometimes dressed a blister with sterile dressing. Foot blisters which were not dressed were prone to infection that led to foot ulcers. Dressing of such blisters was significantly associated with prevention of foot ulcers. These results are similar to those reported by Amogne, Reja, \& Amare [17] in a study on diabetic foot diseases in Ethiopia.

Few patients reported to check inside their shoes before wearing them. However, this was not significantly associated with development of foot ulcers. In a study done in a rural area by Selvakumar \& Shah [18] revealed that none of the patients checked inside their shoes before wearing them.

On the practices of foot care, in this study, using Lukewarm water for washing feet, daily changing of socks, skin care of the feet, and not to apply cream between toes was significantly associated with good practice of foot care. In Malaysia, similar results were reported however in that study checking of temperature of water used to wash the feet was poorly done [19].

Wearing of shoes with socks often, often ensuring the feet and between the toes are dry were significantly associated with increased prevention of foot ulcers. In this study, few patients were practising these ideal practices. This was 
associated with knowledge deficit on ideal foot care practices.

\section{Conclusion}

Based on the researchers findings, religion, source of income, level of education and gender did not affect significantly the practice of the ideal self foot care practice. The age of the respondent, their smoking status and the duration they had lived with the diabetes disease significantly determined the development of foot ulcers. On practice of foot care practices, wearing shoes without socks, walking bare foot was associated with risk of developing foot ulcers while dressing of blisters with a sterile dressing, drying feet after washing and drying in between the toes was associated with the prevention of developing foot ulcers.

\section{Recommendations}

The Government of Kenya through the Ministry of Health should engage the county government to carry out intensive campaigns on practice of the recommended diabetic foot care practices in management of diabetes to reduce the burden on drug procurement and promote good health of her citizens.

The health care provider to ensure availability of the charts used to demonstrate ideal foot care practices.

\section{Conflicts of Interest}

The authors declare no conflicts of interest regarding the publication of this paper.

\section{References}

[1] Martínez-De Jesús, F. (2013) A Checklist System to Score Healing Progress of Diabetic Foot Ulcer. International Journal of Lower Extremity Wounds, 9, 74-83. https://doi.org/10.1177/1534734610371594

[2] International Diabetis Federation, IDF (2017) IDF Diabetic Atlas. 6 Edition, Brussels, Belgium.

[3] World Health Organization, WHO (2017) Global Reports on Diabetes http://www.who.int/mediacentre/factsheets/fs312/en/

[4] Pengzi, Z., Jing, L. and Yali, J. (2017) Global Epidemiology of Diabetic Foot Ulceration: A Systemic Review and Meta-Analysis. Annals of Medicine, 49, 106-116. https://doi.org/10.1080/07853890.2016.1231932

[5] Abbas, Z. and Archibald, K. (2015) Epidemiology of the Diabetic Foot in Africa. Medical Science Monitor, 11, 262-270.

[6] Abbas, Z., Lutale, J., Baker, N. and Archibald, L. (2011) The 'Step by Step' Diabetic Foot Project in Tanzania: A Model for improving Patient Outcomes in Less Developed Countries. International Wound Journal, 8, 169-175. https://doi.org/10.1111/j.1742-481X.2010.00764.x

[7] Mcferran, L. (2014) Obstacles to Diabetic Care in Kenya. Medical Journal of Therapeutics Africa, 2, 127-129.

[8] Odour, P. and Ondari, N. (2016) The Prevalence of Diabetic Foot at Risk in Kenyatta National Hospital. International Journal of Research and Innovation, 3. 
[9] Jain, A. (2014) A New Classification (Grading System) of Debridement of Diabetic Lower Limbs-An Improvization and Standardization in Practice of Diabetic Lower Limbs Salvage around the World. Medicine Science, 3, 991-1001. https://doi.org/10.5455/medscience.2013.02.8093

[10] Chu, Y. and Wang, P. (2016) Clinical Outcome of Toe Amputation Patients with Type 2 Diabetes in Tianjin, China. International Wound Journal, 13, 175-181. https://doi.org/10.1111/iwj.12249

[11] Walsh, J., Hoffstad, O., Sullivan, M. and Margolis, D. (2016) Association of Diabetic foot Ulcer and Death in a Population Based Cohort from the United Kingdom. Diabetic Medicine, 33, 1493-1498. https://doi.org/10.1111/dme.13054

[12] Padma, K., Beles, S., Bodhere, N. and Valsangkar, S. (2012) Evaluation of Knowledge and Self Care Practices in Diabetic Patients and Their Role in Disease Management. National Journal of Community Medicine, 3, 3-6.

[13] Rocha, R., Zanetti, M. and Santos, M. (2013) Behavior and Knowledge; Basis for Prevention for Diabetic Foot. Acta Paulista de Enfermagem, 22, 17-23. https://doi.org/10.1590/S0103-21002009000100003

[14] Call-paschal, A., Duran, A. and Benedi, A. (2001) Reduction in Foot Ulcer Incidence. Diabetes Care.

[15] Fisher, A.A., Stoeckel, J.E., Laing, J.E. and Townsend, J. (1991) Handbook for Family Planning Operation Research Design. Population Council, New York.

[16] Taksande, B., Thote, M. and Jajoo, U. (2017) Knowledge, Attitude and Practice of Foot Care in Patients with Diabetes at Central Rural INDIA. Journal of Family Medicine and Primary Health Care, 6, 284-287. https://doi.org/10.4103/2249-4863.219994

[17] Amogne, W., Reja, A. and Amare, A. (2013) Diabetic Foot Disease in Ethiopian Patients; A Hospital Based Study. Ethiopian Journal of Health Development, 25, 17-21. https://doi.org/10.4314/ejhd.v25i1.69841

[18] Selvakumar, S. and Shah, P. (2016) Awareness and Practice Regarding Foot Self-Care among Patients of Known Type 2 Diabetes Mellitus in a Rural Area. International Journal of Community Medicine and Public Health, 3, 861-864. https://doi.org/10.18203/2394-6040.ijcmph20160917

[19] Muhammad-Lutfi, A., Zaraihah, M. and Anuar-Ramdhan, I. (2014) Knowledge and Practice of Diabetic Foot Care in an in-Patient Setting at a Tertiary Medical Center in Malaysia. Malaysia Orthopedic Journal, 8, 22-26. https://doi.org/10.5704/MOJ.1411.005 